\title{
From 3D to 3D: isolation of mesenchymal stem/stromal cells into a three-dimensional human platelet lysate matrix
}

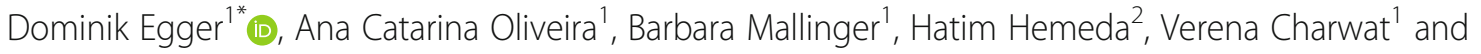
Cornelia Kasper ${ }^{1}$

\begin{abstract}
Background: Mesenchymal stem/stromal cells (MSCs) are considered an important candidate in cell therapy and tissue engineering approaches. The culture of stem cells in a 3D environment is known to better resemble the in vivo situation and to promote therapeutically relevant effects in isolated cells. Therefore, the aim of this study was to develop an approach for the direct isolation of MSCs from adipose tissue into a 3D environment, avoiding contact to a 2D plastic surface. Furthermore, the use of a cryoprotective medium for the cryopreservation of whole adipose tissue was evaluated.
\end{abstract}

Materials and methods: Cryopreservation of fresh adipose tissue with and without a cryoprotective medium was compared with regard to the viability and metabolic activity of cells. After thawing, the tissue was embedded in a novel human platelet lysate-based hydrogel for the isolation of MSCs. The migration, yield, viability, and metabolic activity of cells from the 3D matrix were compared to cells from 2D explant culture. Also, the surface marker profile and differentiation capacity of MSCs from the 3D matrix were evaluated and compared to MSCs from isolation by enzymatic treatment or 2D explant culture.

Results: The cryopreservation of whole adipose tissue was found to be feasible, and therefore, adipose tissue can be stored and is available for MSC isolation on demand. Also, we demonstrate the isolation of MSCs from adipose tissue into the 3D matrix. The cells derived from this isolation procedure display a similar phenotype and differentiation capacity like MSCs derived by traditional procedures.

Conclusions: The presented approach allows to cryopreserve adipose tissue. Furthermore, for the first time, MSCS were directly isolated from the tissue into a soft 3D hydrogel environment, avoiding any contact to a 2D plastic culture surface.

Keywords: Mesenchymal stem/stromal cells, Stem cell isolation, 3D cell culture, Platelet lysate, Adipose tissue, Cryopreservation

\section{Introduction}

Mesenchymal stem/stromal cells (MSCs) are an important source for cell therapy and tissue engineering applications. They comprise a heterogeneous cell population derived from the mesenchyme and are predominantly isolated from the bone marrow [1], adipose tissue [2], and birth-associated tissues and fluids [3-5]. However,

\footnotetext{
* Correspondence: dominik.egger@boku.ac.at

${ }^{1}$ Department of Biotechnology, University of Natural Resources and Life Science, Vienna, Austria

Full list of author information is available at the end of the article
}

they are also present in a variety of other tissues, such as tendons [6], ligaments [7], or skin [8]. MSCs are defined by plastic adherence, trilineage differentiation (adipogenic, chondrogenic, osteogenic), and a specific surface marker expression profile $\left(\mathrm{CD}_{105^{+}}, \mathrm{CD} 3^{+}, \mathrm{CD} 90^{+}\right.$, $\mathrm{CD} 14^{-}, \mathrm{CD} 19^{-}, \mathrm{CD} 34^{-}, \mathrm{CD} 45^{-}$, and HLA-DR $\left.{ }^{-}\right)[9,10]$. The regenerative potential of MSCs is not limited to their high in vitro proliferation potential and their ability to differentiate into adipocytes, chondrocytes, and osteoblasts. Also, in vitro differentiation to neurons [11], cardiomyocytes [12], and corneal epithelial cells [13] was 
observed. Effects related to injury repair were also reported, such as migration to injury sites [14], immunomodulatory and anti-inflammatory properties mediated by cellular crosstalk, secretion of trophic factors [15], angiogenesis [16], and anti-scarring effects [17].

Adipose tissue represents an easily accessible and ethically not questionable source of MSCs. The cells are usually isolated by mechanical dissociation and subsequent enzymatic digestion of the tissue with collagenase [18]. However, it was shown that commercially available collagenase products may contain endotoxins $[19,20]$ and other impurities, including unwanted proteases, since they are rarely purified products. Also, cells that undergo enzymatic digestion were demonstrated to show decreased viability due to lytic activity of the enzyme [21]. To avoid damage by enzymatic digestions or impurities, MSCs were also isolated by explant culture of adipose tissue [22, 23]. Nevertheless, the final step in both isolation procedures is the selection of MSCs by adherence to a 2D plastic surface. However, the isolation procedure and the culture conditions during isolation can select subpopulations of MSCs and affect their function and potency [24]. Furthermore, cultivating MSCs in a 3D environment, either on scaffolds or scaffold-free as aggregates, is known to better reflect the physiological environment of MSCs and to have effects on cellular behavior and functionality [25-27]. Still, to the best of our knowledge, only one procedure for the isolation of MSCs into a 3D environment, avoiding selection by plastic adherence on a 2D surface, is available [28]. Papadimitropoulos et al. developed this procedure to isolate cells from a bone marrow aspirate on a perfused 3D scaffold to avoid 2D plastic adherence. Although this method allows for a streamlined MSC expansion in a bone marrow-like environment, it is limited to hard and porous scaffolds, such as ceramics. Therefore, in this study, we present an approach for the direct isolation of MSCs from adipose tissue into a soft 3D environment. For this, we used a hydrogel matrix prepared from polymerized human platelet lysate (hPL). This hydrogel has the advantage that it serves both as adhesion matrix and nutrient supply, and it was already been shown to be suitable for 3D cell culture of MSCs [29, 30]. Furthermore, it is of increasing interest to have human adipose tissue for the isolation of MSCs available at any time. Since fresh donor tissue is not always available on demand, strategies for the cryopreservation of human adipose tissue are required. The cryopreservation of liposuction aspirates from adipose tissue and isolation of MSCs by enzymatic treatment from long-term cryopreserved adipose tissue was demonstrated before [31, 32]. However, we aimed to develop an approach for the cryopreservation for whole adipose tissue portions for the isolation of MSCs by explant cultivation. For this, we tested the cryopreservation with and without a cryoprotective medium. Altogether, we aimed to develop a workflow for the cryopreservation of adipose tissue which then can be used for the embedding in a 3D matrix for the isolation of MSCs from their native 3D environment into a $3 \mathrm{D}$ matrix, avoiding contact to a $2 \mathrm{D}$ plastic surface.

\section{Materials and methods}

\section{Freezing and thawing of adipose tissue}

The adipose tissue used in this study was derived from abdominal plastic surgery of four different donors (female, 28-58 years old), as described before [33]. The tissue was manually cut into pieces of approximately 125 $\mathrm{mm}^{3}$, as a maximum side length of $5 \times 5 \times 5 \mathrm{~mm}$ was intended. Afterwards, $1 \mathrm{~g}$ (corresponding to approximately eight pieces) of tissue was transferred to a vial for cryopreservation (Greiner Bio-One, Kremsmünster, Austria), covered with a medium for cryopreservation composed of MEM alpha (Thermo Fisher Scientific, Waltham, MA, USA) supplemented with $12.5 \% \mathrm{hPL}$ (PLSolution; PL BioScience, Aachen, Germany) and 10\% dimethyl sulfoxide (DMSO; Sigma Aldrich, St. Louis, MO, USA) or left without a medium and subsequently cooled down at $1{ }^{\circ} \mathrm{C} / \mathrm{min}$ to $-80^{\circ} \mathrm{C}$. After $24 \mathrm{~h}$, the tissue was stored in liquid nitrogen $\left(-196^{\circ} \mathrm{C}\right)$. Upon thawing, the vials were placed in a $37^{\circ} \mathrm{C}$ water bath for 2 min, the medium was removed, and the pieces either transferred to a standard cell culture plate or embedded into a gel comprised of polymerized hPL as described in the "Isolation via 2D explant culture" section and "Isolation via 3D explant culture" section.

\section{Isolation via 2D explant culture}

For the isolation via the 2D explant culture, one thawed tissue piece (cryopreserved without a medium) was transferred to tissue culture-treated 24-well plates and incubated for $1 \mathrm{~h}$ at $37^{\circ} \mathrm{C}$ to let the tissue attach to the surface. Some experiments were performed in a 6-well plate. In this case, three pieces of tissue were transferred to one well. Afterwards, the tissue was covered with an expansion medium composed of MEM alpha with 10\% hPL, 0.5\% gentamycin (Lonza, Basel, Switzerland), and 1 $\mathrm{U} / \mathrm{ml}$ PLSupplement (heparin; PL BioScience GmbH) and incubated in a standard incubator. For better comparison, the tissue was covered with the same volume of medium as the volume of PLMatrix (PL BioScience $\mathrm{GmbH}$, Aachen, Germany) used during 3D explant culture (refer to the "Isolation via 3D explant culture" section), and no medium changes were performed. After 14 days, the cells were detached by accutase (Sigma Aldrich) treatment $\left(15-\mathrm{min}\right.$ incubation at $\left.37^{\circ} \mathrm{C}\right)$, and the total cell number was determined by trypan blue staining and manual counting with a hemocytometer. The 
standard enzymatic isolation procedure from adipose tissue was performed as described before [33].

\section{Isolation via 3D explant culture}

For the isolation via 3D explant culture, adipose tissue was embedded between two layers of a hPL-based gel, which was composed of $10 \%$ reconstituted lyophilized PLMatrix (PL BioScience GmbH, Aachen, Germany) in MEM alpha with $0.5 \%$ gentamycin. First, a bottom layer was added to 6- or 24-well plates and polymerized for 1 $\mathrm{h}$ at $37^{\circ} \mathrm{C}$ in a standard incubator. As for the $2 \mathrm{D}$ explant culture, either three or one thawed tissue pieces (cryopreserved without medium) were transferred on top of the bottom layer in a 6- or 24-well plate, respectively, covered with a top layer of PLMatrix and incubated at $37^{\circ} \mathrm{C}$ for up to 14 days.

\section{Harvesting of MSCs from PLMatrix}

The cells that were cultured in the PLMatrix were harvested by combining mechanical dissociation and enzymatic digestion of the extracellular matrix (ECM). The gel was dissociated by suction through the needle of a 5ml syringe (both Braun, Kronberg im Taunus, Germany), and the liquid gel, together with the tissue, was transferred to a centrifugation tube. The well was rinsed with phosphate-buffered saline (PBS; Sigma Aldrich), transferred to the same tube, and the tube was centrifuged at $500 \mathrm{~g}$ for $5 \mathrm{~min}$. After removal of the supernatant and the adipose tissue, the cell pellet was resuspended in $2 \mathrm{ml}$ of $2 \mathrm{mg} / \mathrm{ml}$ collagenase IA (Sigma Aldrich) in PBS and incubated for $1 \mathrm{~h}$ at $37^{\circ} \mathrm{C}$ on a horizontal shaker at 100 $\mathrm{rpm}$. Afterwards, the tube was centrifuged at $500 \mathrm{~g}$ for 5 min and the pellet resuspended in the expansion medium. The total cell number was then determined by trypan blue staining and manual cell counting with a hemocytometer.

\section{Differentiation}

To determine the adipogenic and osteogenic differentiation capacity, 4,000 cells $/ \mathrm{cm}^{2}$ in passage 2 were seeded on a 12-well plate coated with fibronectin $\left(2 \mu \mathrm{g} / \mathrm{cm}^{2}\right.$; Sigma Aldrich) and allowed to grow confluent. For chondrogenic differentiation, $2.5 \times 10^{5}$ cells were seeded into a $15-\mathrm{ml}$ tube and centrifuged $(300 \mathrm{~g}, 5 \mathrm{~min})$ to form an aggregate. Then, in all conditions, the medium was changed to adipogenic, chondrogenic (NH AdipoDiff Medium or NH ChondroDiff Medium, both Miltenyi Biotech, Bergisch Gladbach, Germany, with 0.5\% gentamycin), or osteogenic differentiation medium (MEM alpha, 2.5\% HPL, $0.5 \%$ gentamycin, $1 \mathrm{U} / \mathrm{ml}$ heparin, 5 $\mathrm{mM}$ beta-glycerolphosphate, $0.1 \mu \mathrm{M}$ dexamethasone, and $0.2 \mathrm{mM}$ L-ascorbate-2-phosphate, all Sigma Aldrich), respectively. Cells were cultivated for 21 days, and the medium was changed every $2-3$ days.

\section{Histological stainings}

MSCs cultivated in the adipogenic medium were stained for lipid vacuoles with Oil Red O, after fixation with 4\% paraformaldehyde (PFA; both Sigma). To confirm chondrogenic differentiation, the aggregates were fixed with 4\% PFA, embedded in paraffin, and stained for glycosaminoglycans with Alcian blue (Sigma) according to routine histology protocols. MSCs cultivated in the osteogenic medium were fixed with $96 \%$ ethanol and stained for calcium with Alizarin Red (Sigma). Cells on day 0 and day 21 cultivated in the expansion medium served as the control. All stainings were performed as described before in detail [27].

\section{Preparation of histological sections}

To prepare histological sections of PLMatrix, the matrix with adipose tissue and migrated cells was fixed with $4 \%$ PFA for $24 \mathrm{~h}$, embedded in paraffin using a Shandon Tissue Excelsior (Thermo Fisher Scientific), and cut with a rotating microtome (Thermo Fisher Scientific). Subsequently, the sections were stained with hematoxylin (Richard Allan Scientific) and eosin (Carl Roth) in $\mathrm{dd}_{2} \mathrm{O}$ and dehydrated, before sections were covered with DPX mounting medium (Sigma Aldrich).

\section{Nuclear staining in PLMatrix}

Prior to staining the cell nuclei with 4',6-diamidin-2phenylindol (DAPI), the samples were fixed with $4 \%$ PFA (both Sigma Aldrich). The cells from standard cell culture plastic surfaces were rinsed with PBS, whereas the PLMatrix samples were not rinsed. Afterwards, the samples were covered with DAPI $1 \mu \mathrm{l} / \mathrm{ml}$ in PBS with $0.1 \%$ Triton X (Sigma Aldrich) and incubated for $30 \mathrm{~min}$ at room temperature. Subsequently, the staining solution was discarded, PBS added, and the staining documented by fluorescence microscopy (Leica, DMIL LED, EL6000).

\section{Live/dead staining}

Viability of cells was visualized with calceinacetoxymethyl ester (AM) and propidium iodide (PI) staining. Briefly, the samples were covered with calceinAM $(2 \mu \mathrm{M})$ and PI $(8 \mu \mathrm{M})$ in PBS and incubated for 30 min at $37^{\circ} \mathrm{C}$. The cells from standard cell culture plastic surfaces were rinsed with PBS prior to incubation. After incubation, all samples were rinsed with PBS and the staining documented by fluorescence microscopy.

\section{Metabolic activity}

To assess the metabolic activity of cells after isolation, the cells were first harvested and incubated with collagenase to obtain single cells as described in the "Harvesting of MSCs from PLMatrix" section. Afterwards, cells were seeded at $1 \times 10^{4}$ cells $/ \mathrm{cm}^{2}$ on standard cell culture plates in an expansion medium and incubated overnight 
at $37^{\circ} \mathrm{C}$. Subsequently, a resazurin-based in vitro toxicology assay kit (TOX8) was applied (Sigma Aldrich) and fluorescence intensity was measured with a plate reader (Tecan, Männedorf, Switzerland) according to the manufacturer's instructions. The expansion medium served as a control.

\section{Phenotyping}

To determine MSC surface marker expression, the cells of one donor were detached by accutase treatment and stained with a human MSC phenotyping kit and an antiHLA-DR antibody (both Miltenyi Biotec) according to the manufacturer's instructions. In this kit, the antibodies for the negative markers (CD14, CD20, CD34, and $\mathrm{CD} 45$ ) are labeled with the same fluorophore to generate a negative marker panel. According to the manufacturer's manual, an approximately 10 -fold increase of the fluorescence intensity of the negative markers is expected for negative samples, as compared to the isotype control. The stained cells were resuspended in a suitable volume of flow cytometry buffer $(0.5 \%$ fetal bovine serum, $2 \mathrm{mM}$ EDTA in PBS), and acquisition was carried out on a BD FACS Canto II (Franklin Lakes, NJ, USA). Between 1 and $5 \times 10^{4}$ gated events were recorded per sample. Subsequent analysis was performed with Kaluza Flow Cytometry software (version 1.3, Beckman Coulter, Brea, CA, USA).

\section{Statistical analysis}

All data is expressed as mean values \pm standard deviation (SD). The data was analyzed using Microsoft Excel and GraphPad Prism 6.01. Comparisons were carried out using unpaired $t$ tests. Values of $p<0.05$ with a confidence interval of $95 \%$ were defined as statistically significant.

\section{Results}

\section{Cryopreservation of adipose tissue}

We tested if our standard medium for cryopreservation of MSCs (12.5\% hPL, 10\% DMSO in MEM alpha) would also be suitable for the cryopreservation of small pieces of human adipose tissue (approximately $125 \mathrm{~mm}^{3}$ ) and tested this condition against cryopreservation without a medium or additional cryoprotectives. After thawing, the tissue was embedded in PLMatrix for the isolation of cells. The outgrowth of cells was observed in both conditions, and no significant difference was observed during 14 days (Fig. 1b). The number of viable cells harvested from the PLMatrix was significantly higher after cryopreservation with a medium, compared to cryopreservation without a medium $(1.9 \pm 0.3$ vs. $1.1 \pm$ $0.1 \times 10^{5}$ cells). The overall viability was similar after cryopreservation with and without a medium $(91 \pm 5 \%$ vs. $95 \pm 13 \%$ ). However, the metabolic activity of cells after isolation and harvest was significantly higher $(1.5 \pm$ 0.2 fold) in cells cryopreserved without a medium, compared to cells cryopreserved with a medium (Fig. 1e).

\section{Migration of MSCs into PLMatrix}

In this study, we compared the migration of cells from the adipose tissue into the PLMatrix with the migration of cells on a standard 2D surface (2D explant) over a period of 14 days. Individual cells were visible in the matrix as early as $72 \mathrm{~h}$ after embedding the tissue into PLMatrix (Additional file 1: Figure S1 and Additional file 2: Video S1). After that, the cells continued to migrate out and proliferated until day 14, as demonstrated by histological sections of the gel and micrographs (Fig. 2, Additional file 3: Figure S2). As the number of harvested cells did not change significantly after 11 days, observations were discontinued at day 14 . Generally, more cells could be harvested from the PLMatrix compared with 2D explant (Fig. 2c). Most of the cells were found to be viable in both conditions, as confirmed by calcein-AM and PI staining (Fig. 2e).

\section{Characterization of MSCs derived by 3D explant isolation}

Cells that migrated into the PLMatrix were found to differentiate into all three lineages, as confirmed by histological stainings (Additional files 4, 5, and 6: Figures S3 to S5). Furthermore, they displayed the same differentiation potential as cells derived from the traditional 2D enzymatic isolation procedure. To characterize the surface marker expression, cells harvested from standard enzymatic isolation procedure (2D control), 2D explant procedure, and PLMatrix were stained for CD105, CD73, CD90, CD14, CD19, CD34, CD45, and HLA-DR and analyzed by flow cytometry. The isolated cells were found to be positive for CD73, CD90, and CD105 and negative for CD14, CD20, CD34, CD45, and HLA-DR. The surface marker profile and average marker expression, as compared to the isotype control, were similar across all conditions (Fig. 3).

\section{Discussion}

In this study, we aimed to develop a workflow for the cryopreservation of whole adipose tissue and further isolation of MSCs into a 3D environment, avoiding contact to a $2 \mathrm{D}$ plastic surface. The cryopreservation of adipose tissue was found to be feasible with and without a standard DMSO containing cryoprotective medium. DMSO is usually used at 5 or $10 \%$ as a cryoprotective agent in cryomedia. Although it is known to cause damage to cells [31], the use of 10\% DMSO (compared to 5\%) increased the recovery and viability of cells after cryopreservation [34], which is why $10 \%$ DMSO was used for cryopreservation in this study. However, the decreased metabolic activity observed in this study might be due to 


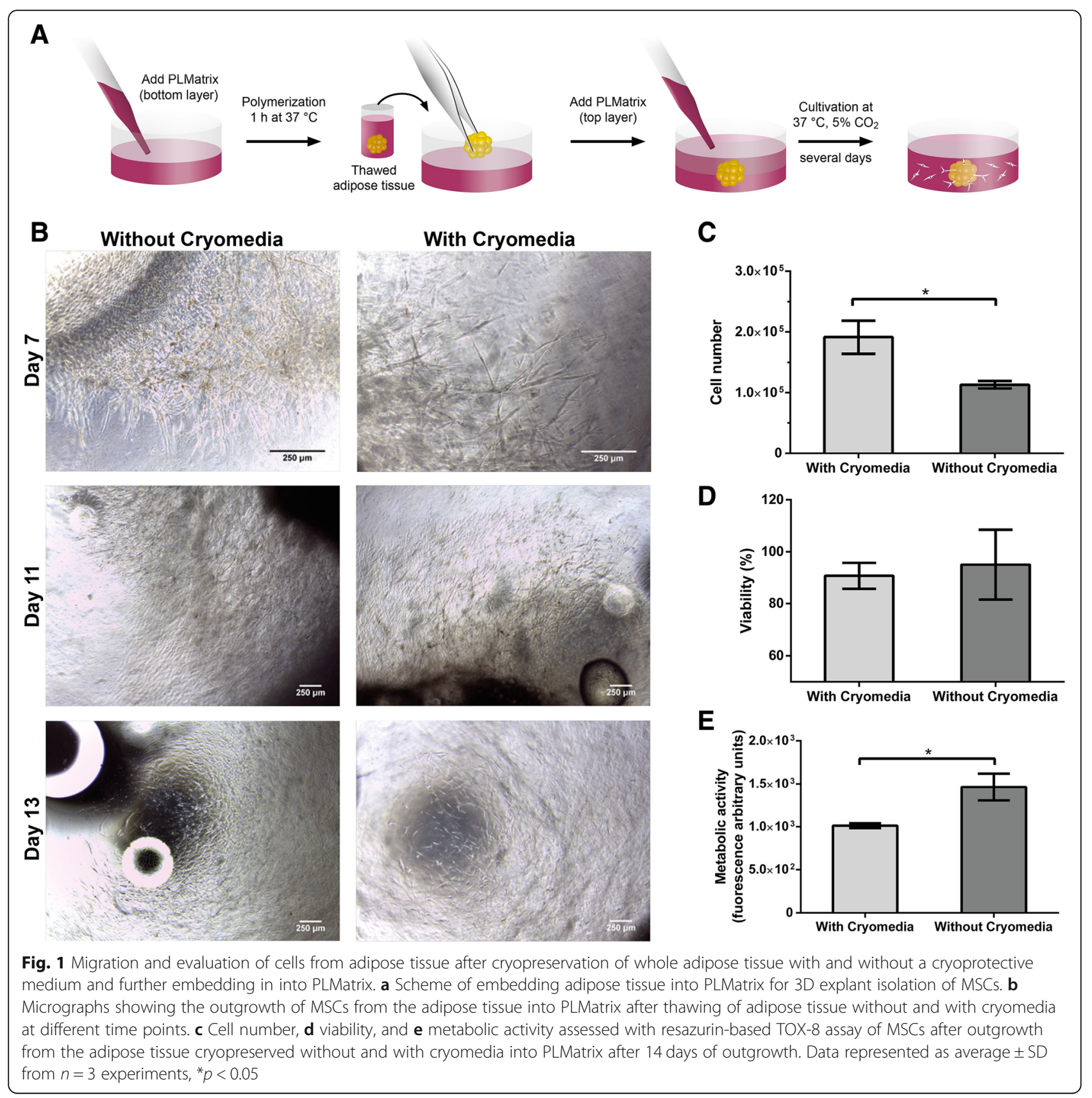

remnants of DMSO in the adipose tissue. This data suggests that cryopreservation of small pieces (approximately $125 \mathrm{~mm}^{3}$ ) of whole adipose tissue with and without a cryoprotective medium is feasible. Although the cell number after thawing was higher when a cryoprotective medium was used, the omission of a cryoprotective medium containing DMSO seems to cause less cell stress and might be more cost- and time-effective in handling. Therefore, we decided to freeze and thaw adipose tissue without a cryoprotective medium for the comparison of 3D vs. 2D explant isolation in this study.
The PLMatrix hydrogel was demonstrated to be suitable for cell culture of MSCs in prior studies [29, 30]. Since the matrix is based on polymerized hPL, the hydrogel serves not only as a structure for migration of the cells but at the same time as nutrient supply. Therefore, the migration of cells from the adipose tissue into the PLMatrix was observed and compared to the migration from the adipose tissue on a standard 2D plastic surface which is usually referred to as explant culture. We found that more cells could be harvested from the PLMatrix compared with the 2D explant (Fig. 2c). This is facilitated by the possibility to migrate from the tissue 


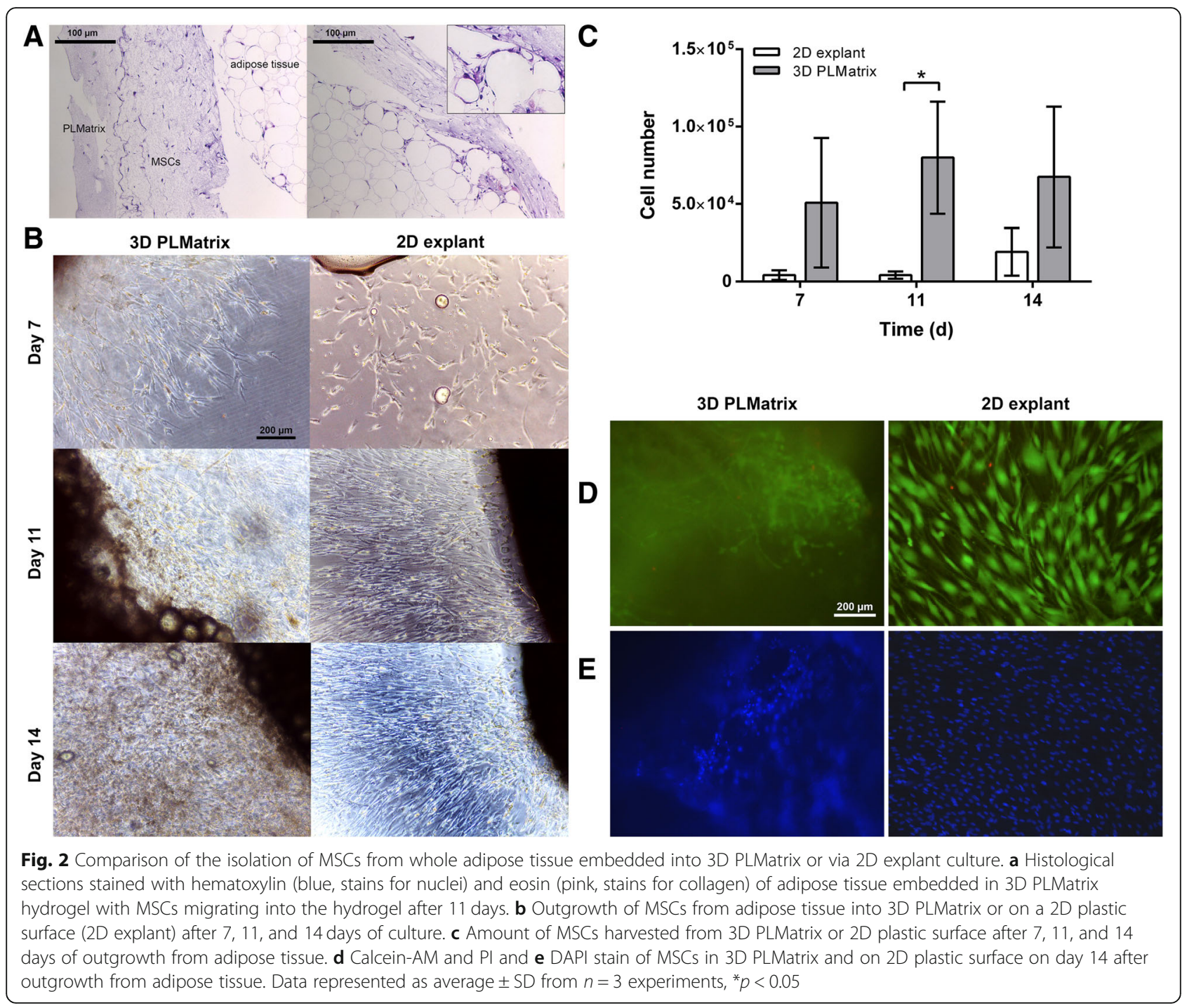

not only in two, but three dimensions. It has already been reported that the isolation of adipose-derived MSCs by explant culture increases the cell yield compared to isolation by enzymatic digestion, while the cells displayed similar comparable immunophenotypic and functional properties [22]. We found that the use of PLMatrix for the isolation of MSCs by explant culture can further increase the yield since cells can grow in all three dimensions, while occupying the same surface area. Interestingly, the histological sections displayed two distinct states of infiltrated areas (Additional file 3: Figure S2). The more distant areas, which were infiltrated by only few cells, barely displayed collagen, as indicated by eosin staining. In comparison, areas with a higher cell density displayed higher amounts of collagen. During the harvest procedure, the collagen was not totally degraded by collagenase treatment, and single cells were found to still be attached to the collagen fibers after digestion. Therefore, optimization of the harvest procedure might further enhance the efficiency and reproducibility of isolation by $3 \mathrm{D}$ explant culture. Also, future approaches need to concentrate on more effective and safe alternatives to avoid the use of collagenase.

Another important factor for future optimization is matrix stiffness, which impacts cell migration, differentiation, and ECM production in a 3D environment [35, 36]. The Young's modulus of PLMatrix was determined prior to use in cell culture and was found to be $0.1 \mathrm{kPa}$ (data not shown), which is close to clinical values for soft tissues. For example, the bone marrow has a Young's modulus of $0.3 \mathrm{kPa}$ [37], the adipose tissue around 1-4 $\mathrm{kPa}[38,39]$, and viable human MSCs around $1 \mathrm{kPa}[40]$. Matrix composition of the surrounding tissue highly affects the elasticity, and major matrix proteins like collagen are known to increase the Young's modulus. As described above, two distinct states of infiltrated areas 


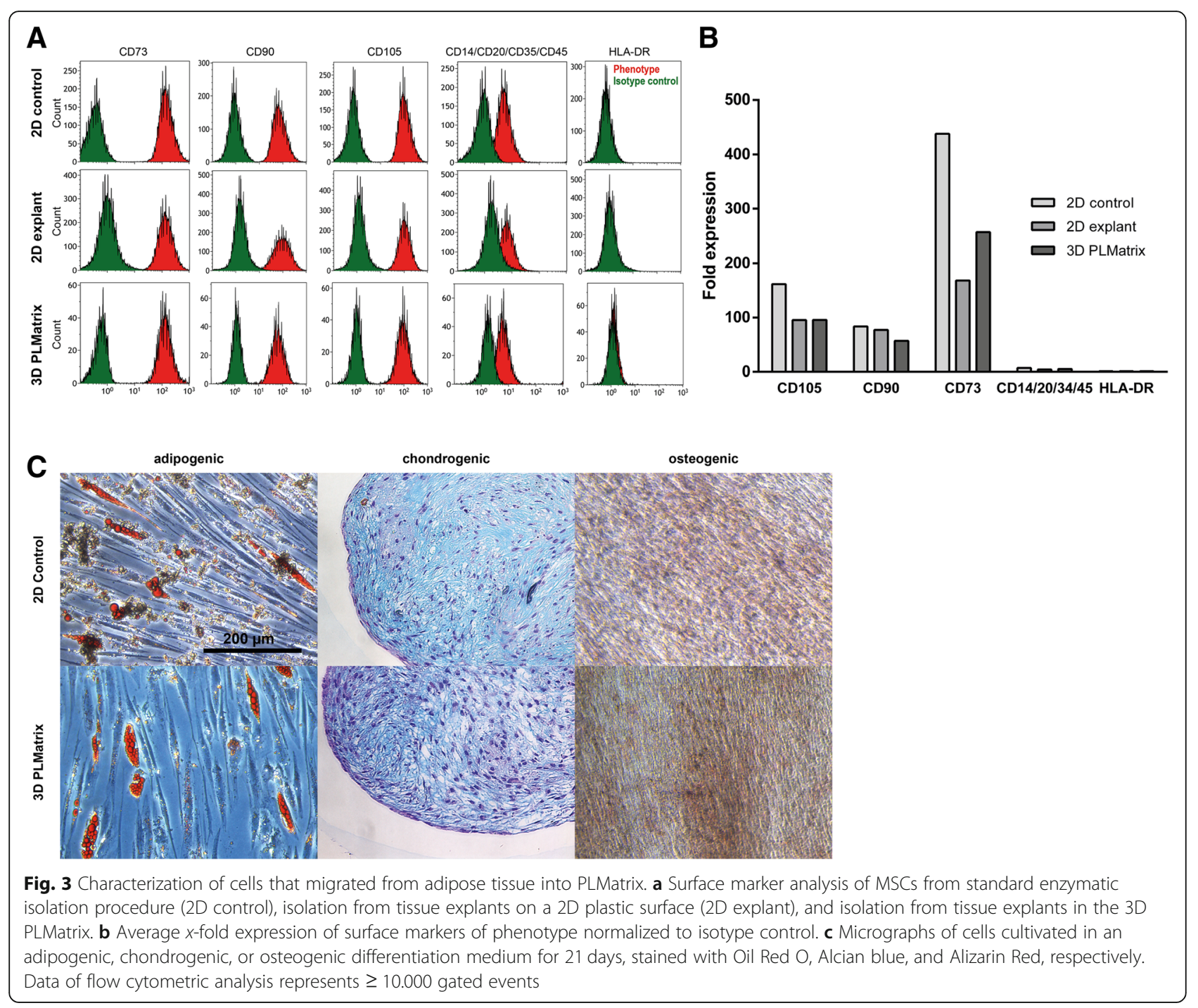

were found in the histological sections (Additional file 3: Figure S2). These observations indicate that the cells started to remodel the hydrogel over time, presumably adjusting the Young's modulus to generate a more physiologic matrix. Previous studies have shown that MSCs display an increased proliferation in hydrogels of higher stiffness $[35,36,41]$. Also, differentiation of MSCs is known to be regulated by substrate stiffness [42]. For example, a stiff substrate was shown to induce osteogenic differentiation, whereas a soft substrate induced neuronal differentiation [36]. Therefore, future work will focus on the development of a tunable hPLbased hydrogel with an increased Young's modulus.

To characterize the cells derived from 3D explant isolation, the differentiation capacity and phenotypic properties of the cells were determined. The cells were able to differentiate into the adipogenic, chondrogenic, and osteogenic lineage (Additional files 4, 5, and 6: Figures S3 to S5). Also, the isolated cells were found to be positive for CD73, CD90, and CD105 and negative for CD14, CD20, CD34, CD45, and HLA-DR which is in accordance with the minimal criteria for the characterization of MSCs [9]. While the surface marker profile and average expression of most markers were similar, the expression of CD73 was found to be altered in cells from 2D explant and PLMatrix, as compared to the 2D control. CD73 is expressed on a variety of cell types and known to be involved in many processes such as the adaption to hypoxia or response to inflammation [43]. Furthermore, a recent publication discussed CD73 as a universal marker for the purification of MSCs after isolation [44]. In this study, a CD $29^{+} \mathrm{CD} 54^{+} \mathrm{CD} 31^{-} \mathrm{CD} 45^{-}$ population isolated from rat bone marrow was identified as MSCs with high colony-forming efficiency and trilineage differentiation capacity. These cells were identical to a population isolated by positive selection of CD73 and uniformly expressed other characteristic MSC markers (CD29, CD44, and CD90). 
In summary, the cells isolated in PLMatrix were found to differentiate into adipogenic, chondrogenic, and osteogenic lineage and to express a MSC-like surface marker profile. Furthermore, the differentiation potential and surface marker profiler was similar to MSCs from the traditional 2D enzymatic isolation procedure. Consequently, these cells were considered as MSCs.

\section{Conclusions}

In this study, we found that small pieces of whole adipose tissue can be frozen and thawed either with a standard cryoprotective medium or even without a medium. The use of a medium with DMSO as a cryoprotective compound increased the yield, but decreased the metabolic activity of cells. Since adipose tissue is often not available on demand, this procedure can potentially be used for long-term storage; however, the quality of MSC after longer storage time will have to be tested in the future. Moreover, to the best of our knowledge, we demonstrate the first approach for the direct isolation of MSCs from tissue into a soft 3D environment, avoiding any contact to a $2 \mathrm{D}$ surface. This process might enable to cultivate MSCs in a physiologic 3D environment for the entire period of in vitro culture. With the use of PLMatrix hydrogel, the 3D environment serves as adhesion matrix and nutrient supply, both of which are promoting cell migration into the matrix. The development of a tunable hPL-based hydrogel with adjustable Young's modulus is planned, in order to increase proliferation during 3D explant isolation, and thus the cellular yield. The cells harvested from the matrix were characterized towards the surface marker profile and differentiation capacity and were found to fulfill the minimal criteria for MSCs. The feasibility of upscaling this approach needs to be evaluated in the future. Also, harvesting procedures need further optimization to increase the cellular yield.

Traditional isolation methods based on enzymatic treatment and selection by 2D plastic surfaces do not represent a physiologic environment. Since 3D culture often leads to a behavior that is more representative of the in vivo situation, the isolation into a 3D environment avoiding any contact with 2D plastic surfaces might contribute to a more physiologic behavior of MSCs. This is desirable, especially in the context of therapeutic approaches and in vitro models, since MSCs display a significantly increased therapeutic potential when cultured in 3D. However, the therapeutic potential of MSCs derived by 3D explant isolation remains to be evaluated by functional assays.

\section{Additional files}

Additional file 1: Figure S1. Time series of micrographs of adipose tissue embedded in PLMatrix over a course of $104 \mathrm{~h}$. Cells migrating from the tissue into the matrix can be observed after $72 \mathrm{~h}$. (JPG $1352 \mathrm{~kb}$ )
Additional file 2: Video S1. Cells migrating from adipose tissue into PLMatrix $48-104 \mathrm{~h}$ after imbedding adipose tissue into PLMatrix. (MP4 $6459 \mathrm{~kb})$

Additional file 3: Figure S2. Histological sections stained with hematoxylin (blue, stains for nuclei) and eosin (pink, stains for collagen). (A) PLMatrix with MSCs that migrated into the hydrogel (the dashed line separates areas where MSCs started to remodel the matrix and areas that are infiltrated by only a few cells). (B) Micrographs covering actual areas of MSC outgrowth from adipose tissue into PLMatrix. (JPG $2257 \mathrm{~kb}$ )

Additional file 4: Figure S3. Cells derived from isolation by enzymatic treatment (2D control) or from 3D isolation (3D PLMatrix) cultivated for 0 or 21 days in control medium (CM) or adipogenic differentiation medium (ADM) stained with Oil Red O. (JPG 2802 kb)

Additional file 5: Figure S4. Histological sections of cells derived from isolation by enzymatic treatment (2D control) or from $3 \mathrm{D}$ isolation (3D PLMatrix) cultivated for 21 days in control medium (CM) or chondrogenic differentiation medium (CDM) stained with Alcian Blue. (JPG $1693 \mathrm{~kb}$ )

Additional file 6: Figure S5. Cells derived from isolation by enzymatic treatment (2D control) or from $3 \mathrm{D}$ isolation (3D PLMatrix) cultivated for 0 or 21 days in control medium (CM) or osteogenic differentiation medium (ODM) stained with Alizarin Red. (JPG 2645 kb)

\section{Acknowledgements}

We thank Maria Egger from mooi-mooi.de for preparing the graphical representation of the workflow (Fig. 1a).

\section{Authors' contributions}

$\mathrm{AO}$ and $\mathrm{BM}$ performed the experiments. $\mathrm{DE}$ designed and performed the experiments, analyzed the data, and wrote the manuscript. VC, $\mathrm{HH}$, and $\mathrm{CK}$ designed the study and reviewed the manuscript. All authors read and approved the final manuscript.

\section{Funding}

This work was partially funded by the "Forschungszentrum Jülich $\mathrm{GmbH}$, Innovationsgutschein F\&E", project number: 322-005-1602-0569.

\section{Availability of data and materials}

The datasets used and/or analyzed during the current study are available from the corresponding author on reasonable request.

\section{Ethics approval and consent to participate}

The use of human tissue was approved by the ethics committee of the Medical University Vienna, Austria (EK Nr. 957/2011, 30 January 2013), and the donor gave written consent.

\section{Consent for publication}

Not applicable.

\section{Competing interests}

The University of Natural Resources and Life Science received PLSolution and PLMatrix from PL BioScience GmbH, Aachen, Germany. Dr. Hatim Hemeda is the executive director of PL BioScience $\mathrm{GmbH}$. The other authors declare that they have no competing interests.

\section{Author details}

'Department of Biotechnology, University of Natural Resources and Life Science, Vienna, Austria. ${ }^{2}$ PL BioScience GmbH, Technology Centre Aachen, Aachen, Germany.

Received: 3 June 2019 Revised: 2 July 2019

Accepted: 15 July 2019 Published online: 09 August 2019

References

1. Conget PA, Minguell JJ. Phenotypical and functional properties of human bone marrow mesenchymal progenitor cells. J Cell Physiol. 1999;181(1):67-73. https://doi.org/10.1002/(SICI)1097-4652(199910)181:1< 67::AID-JCP7>3.0.CO;2-C

2. Hattori H, Sato M, Masuoka K, Ishihara M, Kikuchi T, Matsui T, et al. Osteogenic potential of human adipose tissue-derived stromal cells as an 
alternative stem cell source. Cells Tissues Organs. 2004;178(1):2-12. https:// doi.org/10.1159/000081088.

3. Witkowska-Zimny M, Wrobel E. Perinatal sources of mesenchymal stem cells: Wharton's jelly, amnion and chorion. Cell Mol Biol Lett. 2011;16(3):493-514. https://doi.org/10.2478/s11658-011-0019-7.

4. Moretti P, Hatlapatka T, Marten D, Lavrentieva A, Majore I, Hass R, et al. Mesenchymal stromal cells derived from human umbilical cord tissues: primitive cells with potential for clinical and tissue engineering applications. Bioreactor Systems for Tissue Engineering li: Strategies for the Expanison and Directed Differentiation of Stem Cells. 2010;123:29-54. https://doi.org/1 0.1007/10_2009_15.

5. Hass R, Kasper C, Bohm S, Jacobs R. Different populations and sources of human mesenchymal stem cells (MSC): a comparison of adult and neonatal tissue-derived MSC. Cell Commun Signaling. 2011;9:12. https://doi.org/10.11 86/1478-811X-9-12.

6. Salingcarnboriboon R, Yoshitake H, Tsuji K, Obinata M, Amagasa T, Nifuji A, et al. Establishment of tendon-derived cell lines exhibiting pluripotent mesenchymal stem cell-like property. Exp Cell Res. 2003;287(2):289-300. https://doi.org/10.1016/s0014-4827(03)00107-1.

7. Seo BM, Miura M, Gronthos S, Bartold PM, Batouli S, Brahim J, et al. Investigation of multipotent postnatal stem cells from human periodontal ligament. Lancet. 2004;364(9429):149-55. https://doi.org/10.1016/50140-6736 (04)16627-0.

8. Toma JG, Akhavan M, Fernandes KL, Barnabe-Heider F, Sadikot A, Kaplan $D R$, et al. Isolation of multipotent adult stem cells from the dermis of mammalian skin. Nature Cell Biol. 2001;3(9):778-84. https://doi.org/10.1038/ Ncb0901-778

9. Dominici M, Le Blanc K, Mueller I, Slaper-Cortenbach I, Marini F, Krause D, et al. Minimal criteria for defining multipotent mesenchymal stromal cells. The International Society for Cellular Therapy position statement. Cytotherapy. 2006;8(4):315-7.

10. Bourin P, Bunnell BA, Casteilla L, Dominici M, Katz AJ, March KL, et al. Stromal cells from the adipose tissue-derived stromal vascular fraction and culture expanded adipose tissue-derived stromal/stem cells: a joint statement of the International Federation for Adipose Therapeutics and Science (IFATS) and the International Society for Cellular Therapy (ISCT). Cytotherapy. 2013;15(6):641-8. https://doi.org/10.1016/j.jcyt.2013.02.006.

11. Long XX, Olszewski M, Huang W, Kletzel M. Neural cell differentiation in vitro from adult human bone marrow mesenchymal stem cells. Stem Cells Dev. 2005;14(1):65-9. https://doi.org/10.1089/scd.2005.14.65.

12. Xu WR, Zhang XR, Qian H, Zhu W, Sun XC, Hu J, et al. Mesenchymal stem cells from adult human bone marrow differentiate into a cardiomyocyte phenotype in vitro. Exp Biol Med. 2004;229(7):623-31 <go to ISI>:// 000222398300006

13. Ma YL, Xu YS, Xiao ZF, Yang W, Zhang C, Song E, et al. Reconstruction of chemically burned rat corneal surface by bone marrow-derived human mesenchymal stem cells. Stem Cells. 2006;24(2):315-21. https://doi.org/1 0.1634/stemcells.2005-0046.

14. Oh JY, Kim MK, Shin MS, Lee HJ, Ko JH, Wee WR, et al. The antiinflammatory and anti-angiogenic role of mesenchymal stem cells in corneal wound healing following chemical injury. Stem Cells. 2008;26(4): 1047-55. https://doi.org/10.1634/stemcells.2007-0737.

15. Murphy MB, Moncivais K, Caplan Al. Mesenchymal stem cells: environmentally responsive therapeutics for regenerative medicine. Exp Mol Med. 2013;45. https://doi.org/10.1038/emm.2013.94.

16. Sorrell JM, Baber MA, Caplan Al. Influence of adult mesenchymal stem cells on in vitro vascular formation. Tissue Eng Part A. 2009;15(7):1751-61. https:// doi.org/10.1089/ten.tea.2008.0254.

17. Meirelles LD, Nardi NB. Methodology, biology and clinical applications of mesenchymal stem cells. Front Biosci (Landmark Ed). 2009;14:4281-98. https://doi.org/10.2741/3528.

18. Zuk PA, Zhu M, Ashjian P, De Ugarte DA, Huang Jl, Mizuno H, et al. Human adipose tissue is a source of multipotent stem cells. Mol Biol Cell. 2002; 13(12):4279-95. https://doi.org/10.1091/mbc.E02-02-0105.

19. Jahr H, Pfeiffer G, Hering BJ, Federlin K, Bretzel RG. Endotoxin-mediated activation of cytokine production in human PBMCs by collagenase and Ficoll. J Mol Med-Jmm. 1999;77(1):118-20. https://doi.org/10.1007/s00109005 0316.

20. Vargas F, VivesPi M, Somoza N, FernandezLlamazares J, PujolBorrell R. Endotoxin activity of collagenase and human islet transplantation. Lancet. 1997;350(9078):641. https://doi.org/10.1016/S0140-6736(05)63331-4.
21. Ishige I, Nagamura-Inoue T, Honda MJ, Harnprasopwat R, Kido M, Sugimoto $\mathrm{M}$, et al. Comparison of mesenchymal stem cells derived from arterial, venous, and Wharton's jelly explants of human umbilical cord. Int J Hematol. 2009;90(2):261-9. https://doi.org/10.1007/s12185-009-0377-3.

22. Priya N, Sarcar S, Sen Majumdar A, SundarRaj S. Explant culture: a simple, reproducible, efficient and economic technique for isolation of mesenchymal stromal cells from human adipose tissue and lipoaspirate. J Tissue Eng Regen Med. 2014;8(9):706-16. https://doi.org/10.1002/term.1569.

23. Hendijani F. Explant culture: an advantageous method for isolation of mesenchymal stem cells from human tissues. Cell Prolif. 2017;50(2). https:// doi.org/10.1111/cpr.12334

24. LV FJ, Tuan RS, Cheung KMC, Leung VYL. Concise review: the surface markers and identity of human mesenchymal stem cells. Stem Cells. 2014; 32(6):1408-19. https://doi.org/10.1002/stem.1681.

25. Baker BM, Chen CS. Deconstructing the third dimension - how 3D culture microenvironments alter cellular cues. J Cell Sci. 2012;125(13):3015-24. https://doi.org/10.1242/jcs.079509.

26. Sart S, Tsai AC, Li Y, Ma T. Three-dimensional aggregates of mesenchymal stem cells: cellular mechanisms, biological properties, and applications. Tissue Eng Part B Rev. 2014;20(5):365-80. https://doi.org/10.1089/ten.TEB.2013.0537.

27. Egger D, Schwedhelm I, Hansmann J, Kasper C. Hypoxic three-dimensional scaffold-free aggregate cultivation of mesenchymal stem cells in a stirred tank reactor. Bioengineering (Basel). 2017;4(2). https://doi.org/10.3390/ bioengineering 4020047

28. Papadimitropoulos A, Piccinini E, Brachat S, Braccini A, Wendt D, Barbero A, et al. Expansion of human mesenchymal stromal cells from fresh bone marrow in a 3D scaffold-based system under direct perfusion. PLoS One. 2014;9(7):e102359. https://doi.org/10.1371/journal.pone.0102359.

29. Hemeda H, Giebel B, Wagner W. Evaluation of human platelet lysate versus fetal bovine serum for culture of mesenchymal stromal cells. Cytotherapy. 2014;16(2):170-80

30. Walenda G, Hemeda H, Schneider RK, Merkel R, Hoffmann B, Wagner W. Human platelet lysate gel provides a novel three dimensional-matrix for enhanced culture expansion of mesenchymal stromal cells. Tissue Engineering Part C-Methods. 2012;18(12):924-34. https://doi.org/10.1089/ ten.tec.2011.0541.

31. Choudhery MS, Badowski M, Muise A, Pierce J, Harris DT. Cryopreservation of whole adipose tissue for future use in regenerative medicine. J Surg Res. 2014;187(1):24-35. https://doi.org/10.1016/j.jss.2013.09.027.

32. Devitt SM, Carter CM, Dierov R, Weiss S, Gersch RP, Percec I. Successful isolation of viable adipose-derived stem cells from human adipose tissue subject to long-term cryopreservation: positive implications for adult stem cell-based therapeutics in patients of advanced age. Stem Cells Int. 2015; 2015:146421. https://doi.org/10.1155/2015/146421.

33. Egger D, Spitz S, Fischer M, Handschuh S, Glosmann M, Friemert B, et al. Application of a parallelizable perfusion bioreactor for physiologic 3D cell culture. Cells Tissues Organs. 2017;203(5):316-26. https://doi.org/10.1159/000457792.

34. Ginis I, Grinblat B, Shirvan MH. Evaluation of bone marrow-derived mesenchymal stem cells after cryopreservation and hypothermic storage in clinically safe medium. Tissue Eng Part C-Methods. 2012;18(6):453-63. https://doi.org/10.1089/ten.tec.2011.0395.

35. Rowlands AS, George PA, Cooper-White JJ. Directing osteogenic and myogenic differentiation of MSCs: interplay of stiffness and adhesive ligand presentation. Am J Phys Cell Phys. 2008;295(4):C1037-44. https://doi.org/1 0.1152/ajpcell.67.2008.

36. Li Z, Gong YW, Sun SJ, Du Y, Lu DY, Liu XF, et al. Differential regulation of stiffness, topography, and dimension of substrates in rat mesenchymal stem cells. Biomaterials. 2013;34(31):7616-25. https://doi.org/10.1016/j. biomaterials.2013.06.059.

37. Winer JP, Janmey PA, McCormick ME, Funaki M. Bone marrow-derived human mesenchymal stem cells become quiescent on soft substrates but remain responsive to chemical or mechanical stimuli. Tissue Eng A. 2009; 15(1):147-54. https://doi.org/10.1089/ten.tea.2007.0388.

38. Alkhouli N, Mansfield J, Green E, Bell J, Knight B, Liversedge N, et al. The mechanical properties of human adipose tissues and their relationships to the structure and composition of the extracellular matrix. Am J Physiol Endocrinol Metab. 2013;305(12):E1427-35. https://doi.org/10.1152/ajpendo. 00111.2013 .

39. Comley K, Fleck NA. A micromechanical model for the Young's modulus of adipose tissue. Int J Solids Struct. 2010;47(21):2982-90. https://doi.org/10.1 016/j.jijsolstr.2010.07.001. 
40. Nikolaev NI, Muller T, Williams DJ, Liu Y. Changes in the stiffness of human mesenchymal stem cells with the progress of cell death as measured by atomic force microscopy. J Biomech. 2014;47(3):625-30. https://doi.org/10.1 016/j.jbiomech.2013.12.004

41. Le NNT, Zorn S, Schmitt SK, Gopalan P, Murphy WL. Hydrogel arrays formed via differential wettability patterning enable combinatorial screening of stem cell behavior. Acta Biomater. 2016;34:93-103. https://doi.org/10.1016/j. actbio.2015.09.019.

42. Pek YS, Wan AC, Ying JY. The effect of matrix stiffness on mesenchymal stem cell differentiation in a 3D thixotropic gel. Biomaterials. 2010;31(3):38591. https://doi.org/10.1016/j.biomaterials.2009.09.057.

43. Colgan SP, Eltzschig HK, Eckle T, Thompson LF. Physiological roles for ecto5'-nucleotidase (CD73). Purinergic Signal. 2006;2(2):351-60. https://doi.org/1 0.1007/s11302-005-5302-5.

44. Suto EG, Mabuchi Y, Suzuki N, Suzuki K, Ogata Y, Taquchi M, et al. Prospectively isolated mesenchymal stem/stromal cells are enriched in the CD73(+) population and exhibit efficacy after transplantation. Sci Rep. 2017; 7(1):4838. https://doi.org/10.1038/s41598-017-05099-1.

\section{Publisher's Note}

Springer Nature remains neutral with regard to jurisdictional claims in published maps and institutional affiliations.

Ready to submit your research? Choose BMC and benefit from:

- fast, convenient online submission

- thorough peer review by experienced researchers in your field

- rapid publication on acceptance

- support for research data, including large and complex data types

- gold Open Access which fosters wider collaboration and increased citations

- maximum visibility for your research: over $100 \mathrm{M}$ website views per year

At BMC, research is always in progress.

Learn more biomedcentral.com/submissions 